\title{
Ultimate tensile strength of embedded I-sections: a comparison of experimental and numerical results
}

\author{
Mahmoud Heristchian • Pouyan Pourakbar • \\ Saeed Imeni • M. Reza Adib Ramezani
}

Received: 19 May 2014 / Accepted: 6 November 2014/Published online: 21 November 2014

(c) The Author(s) 2014. This article is published with open access at Springerlink.com

\begin{abstract}
Exposed baseplates together with anchor bolts are the customary method of connection of steel structures to the concrete footings. Post-Kobe studies revealed that the embedded column bases respond better to the earthquake uplift forces. The embedded column bases also, offer higher freedom in achieving the required strength, rigidity and ductility. The paper presents the results of the pullout failure of three embedded IPE140 sections, tested under different conditions. The numerical models are then, generated in Abaqus 6.10-1 software. It is concluded that, the steel profiles could be directly anchored in concrete without using anchor bolts as practiced in the exposed conventional column bases. Such embedded column bases can develop the required resistance against pullout forces at lower constructional costs.
\end{abstract}

Keywords Steel section embedded in concrete Pullout test $\cdot$ Ultimate load $\cdot$ Numerical modelling

\section{Introduction}

Using exposed baseplates and anchor rods is a common method for connection of steel columns to concrete footings. Alternative method for connection of steel columns to concrete is by directly embedding them, with or without end plates, as shown in Fig. 1. In such a structural solution, the overall depth, the dimensions of the footing, the embedding depth and details of the embedded steel element

M. Heristchian $(\square) \cdot$ P. Pourakbar · S. Imeni ·

M. R. A. Ramezani

Islamic Azad University, South Tehran Branch (IAU STB),

Tehran, Iran

e-mail: heris@azad.ac.ir are crucial factors for the load transfer and integrity of the connection. In general, the steel element may be subjected to axial compressive or tensile forces, as well as shear and bending forces. The main sources of tensile force in a column element are lateral actions such as wind or earthquake loads. Experimentally and numerically, the paper deals with the ultimate response of the embedded steel elements, of the type of Fig. 1, subjected to tensile actions in the absence of shear and moments.

Significant failure of column baseplate connections have been reported in major earthquakes, emphasising not only the importance of their function but also the lack of knowledge of their true behaviour. Based on post-Kobe research, Hitaka et al. (2003), report that larger rotational stiffness is expected for embedded column base than the conventional baseplate connection. Further, they observed that anchor bolts had fractured or elongated severely in Kobe earthquake, whereas no damage was reported for the embedded column connections. Figure 2, shows the pullout failure of an exposed steel column base, in Kobe earthquake, Hitaka et al. (2003).

Nakashima (1992, 1996), Suzuki and Nakashima (1986), Nakashima and Igarashi (1987) studied extensively the behaviour of shallowly embedded column bases under cyclic loading. They embedded the conventional exposed column bases in reinforced concrete. They found that the embedding depth and detailing of the reinforcement around the embedded column base had significant effect on its rigidity, strength and deformation. The deeply embedded column bases, with he $\geq 2 \mathrm{D}$ (where he: embedding depth, D: column width), could guarantee the full fixity of the connections. Recommendations on this embedding depth have been made for different column shapes, Morino et al. (2003). Kohzu et al. (1991), studied very shallow embedded steel column bases under vertical and horizontal 


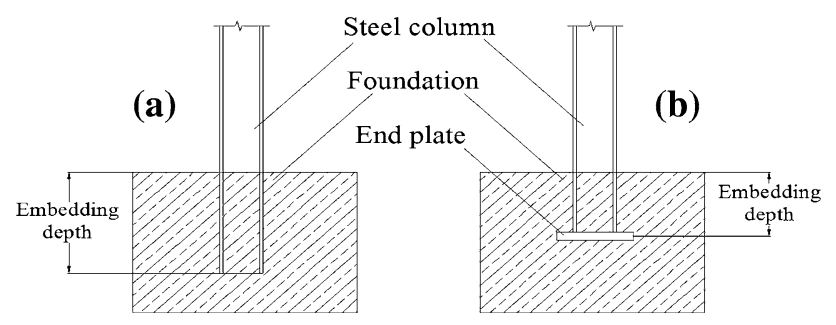

Fig. 1 Embedded column base, a without end plate, $\mathbf{b}$ with end plate

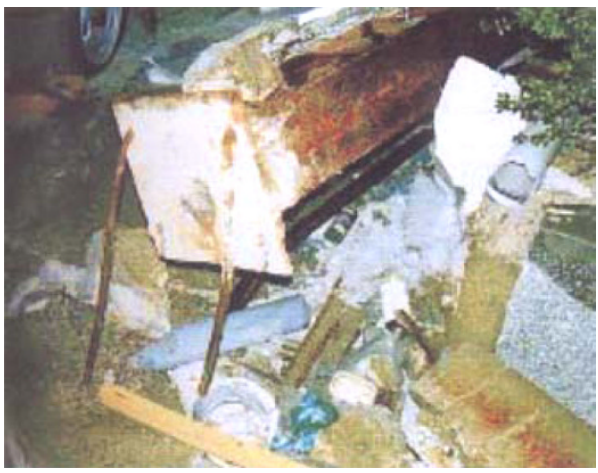

Fig. 2 Exposed column base pullout failure, Kobe (1995), Hitaka et al. (2003)

loading. The general conclusion of the studies is that the embedding of the base plate improves its seismic behaviour by increasing the strength and ductility. The degree of the improvement of the behaviour depends on parameters such as the depth and details of the embedding reinforcement. Recommendations have also been given for wide-flange profiles with embedding depth ranging from $1 \mathrm{D}$ to $2 \mathrm{D}$, Pertold et al. (2000a, b).
Elsewhere, Heristchian et al. (2014), numerically and experimentally, studied the pullout behaviour of tapered I and box steel sections embedded in unreinforced concrete (Fig. 3). The test specimens sustained a relatively large portion of the peak load with a large displacement before pullout from the concrete block. Also, between the 'first' and the 'last' peak loads, the tests show a 'load plateau'. However, with a higher tapering angle $(\alpha)$, the plateau disappeared and the overall displacement decreased. The numerical models, present the effect of boundary conditions, the size of the concrete block, the tapering angle, and the coefficient of friction. As shown in Fig. 4, the restraining boundary conditions prevent the splitting of the concrete block, which is the most common type of failure in embedded tapered sections, and could double its pullout strength. Under proper confinement, the splitting failure changes into the 'biconical' shape and it could have very large post-failure pullout strength. The paper proposes three methods for construction of embedded column bases (Fig. 5).

\section{Experimental work on embedded column base}

To study the tensile behaviour of the embedded column bases with details given in Fig. 1, three experiments were conducted. Structural IPE140 sections of steel S235 were embedded in unreinforced concrete blocks. The concrete blocks were made of the same batch and were tested with concrete age of over 60 days. The axial 'pull-out' load was applied to the embedded profiles and the load was monotonically increased to cause either withdrawal of the steel profiles from the concrete or their rupture. These three
Fig. 3 The concrete block, the load frame and a specimen $(\mathrm{mm})$, Heristchian et al. (2014)

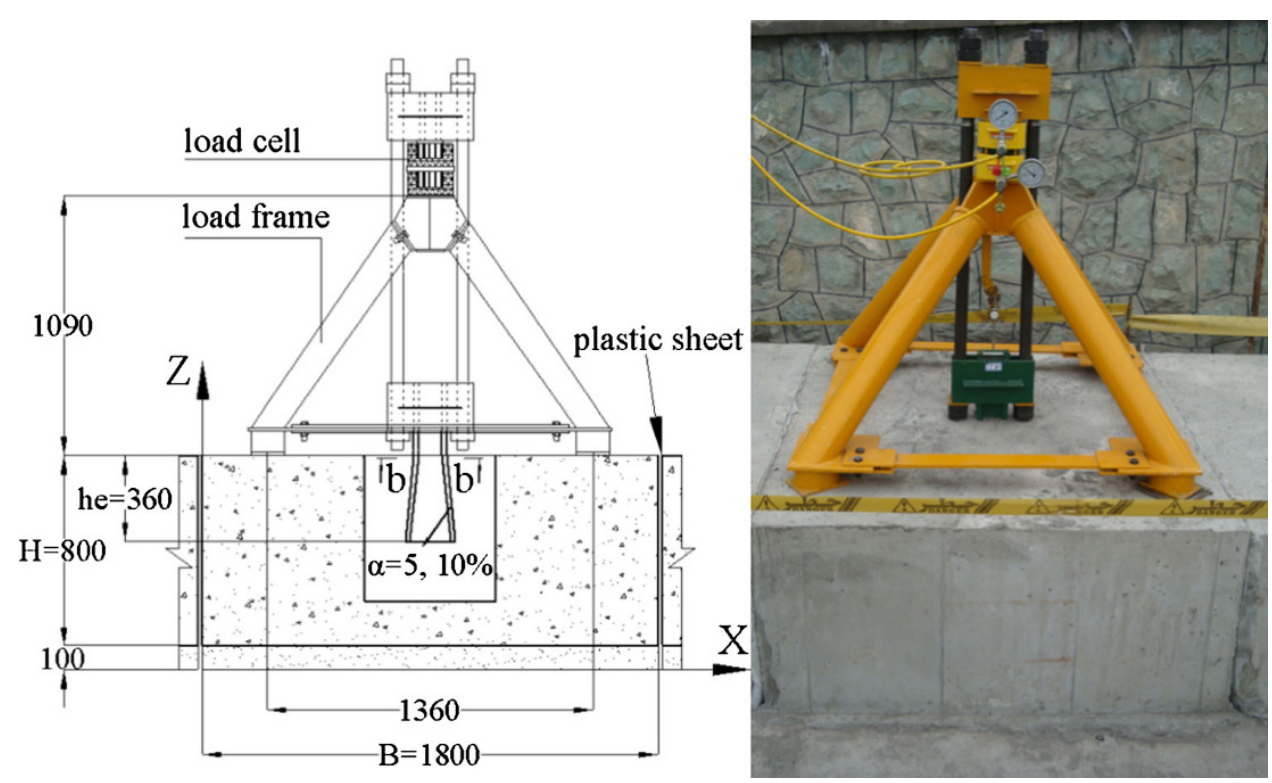


specimens are referred to as M1, M2 and M3. The schematic details of the test setup (plan and section) are presented in Fig. 6. The embedding depth and the end conditions of the IPE sections are given in Fig. 7. The embedding depths were 600, 400 and $200 \mathrm{~mm}$ for specimens M1, M2 and M3, respectively. The specimen M1 did not have end plate but the specimens $\mathrm{M} 2$ and $\mathrm{M} 3$ had end plate of size $200 \times 200 \times 15 \mathrm{~mm}$. As it is seen in Fig. 6, the concrete block had the height of 700 and width of $800 \mathrm{~mm}$. The thickness of the lean concrete beneath the concrete block was $100 \mathrm{~mm}$ and the formwork of the concrete was brickwork with a thickness of $100 \mathrm{~mm}$. The characteristic compressive strength of the concrete was $30 \mathrm{MPa}$. The surface of the IPE steel sections did not receive any specific cleaning treatment prior to embedding. This lack of treatment was to simulate the real construction situation.

A hydraulic jack of nominal capacity $1500 \mathrm{kN}$ was used to pullout the IPE sections from the concrete. The jack (support) reaction was transferred to the concrete at the neighbouring zone of the embedded sections via two plates of dimensions $600 \times 100 \mathrm{~mm}$. The IPE sections were extended $200 \mathrm{~mm}$ above the concrete blocks (section A-A, Fig. 6). Also, at the top of each section a load block (a)

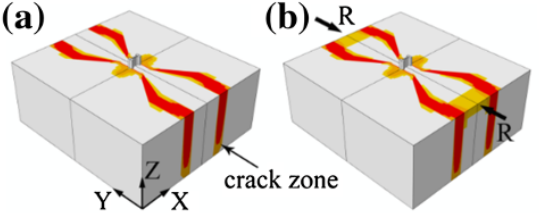

(c)

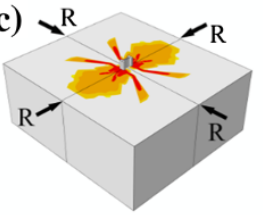

R: Restraint

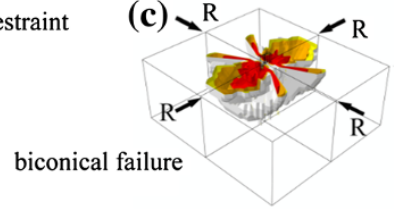

Fig. 4 Failure mechanisms under different boundary conditions, Heristchian et al. (2014) connected the structural section to the hydraulic jack. The load blocks were made of steel plates $40 \mathrm{~mm}$ thickness and were welded to the top of the I-sections. There were six stiffeners welded to each structural I-section and the load block. The vertical displacements were recorded on the right and left sides of the load block (Fig. 7).

The tensile force, with a gradual increase, was applied to the specimens M1 to M3, and the displacements of the top of the specimens were recorded for load values. A description of the results of the tests is presented as follows.

\section{Test M1}

Figure 8, shows the load-displacement diagram for the specimen M1. The diagram gives the records of the load for the displacements at the left and right of the load block of Fig. 7, together with their averages. Up to the load $560 \mathrm{kN}$ the recorded displacements were less than $0.7 \mathrm{~mm}$. The average displacement of $8.2 \mathrm{~mm}$ was corresponding to the maximum load of $682 \mathrm{kN}$. The displacement beyond $8.2 \mathrm{~mm}$ was not recorded. Figure $9 \mathrm{a}$ shows a general view of the test setup, and Fig. 9b shows crushing of the concrete. Figure 9c shows the final pulled out stage of the profile together with the peeling out and damage to the paint of the section indicating the stretching of the profile. This Figure also shows that the flange of the IPE section is slightly bent inside and also has been slightly narrowed, as seen against a straight block placed beside the pulled out section.

\section{Tests M2 and M3}

The load-displacement diagrams for specimens M2 and M3 are shown in Fig. 10. For test M2, the records show significant differences for the right and left. This is caused by unavoidable eccentricity of the setup such as irregularities in the surfaces of contact, non-alignment of
Fig. 5 Three methods for construction of embedded tapered column base, Heristchian et al. (2014)

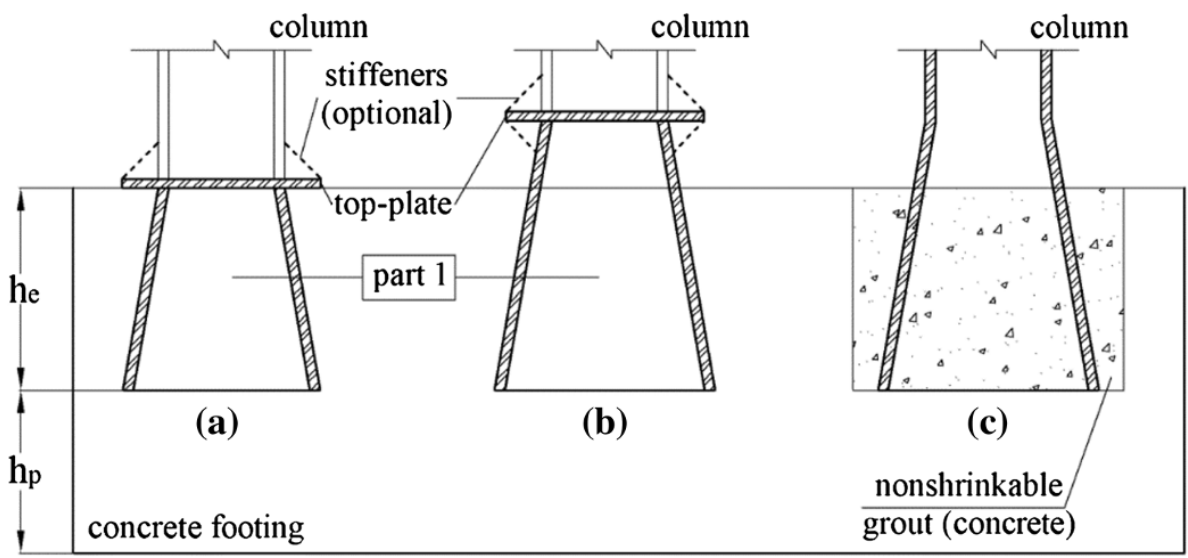




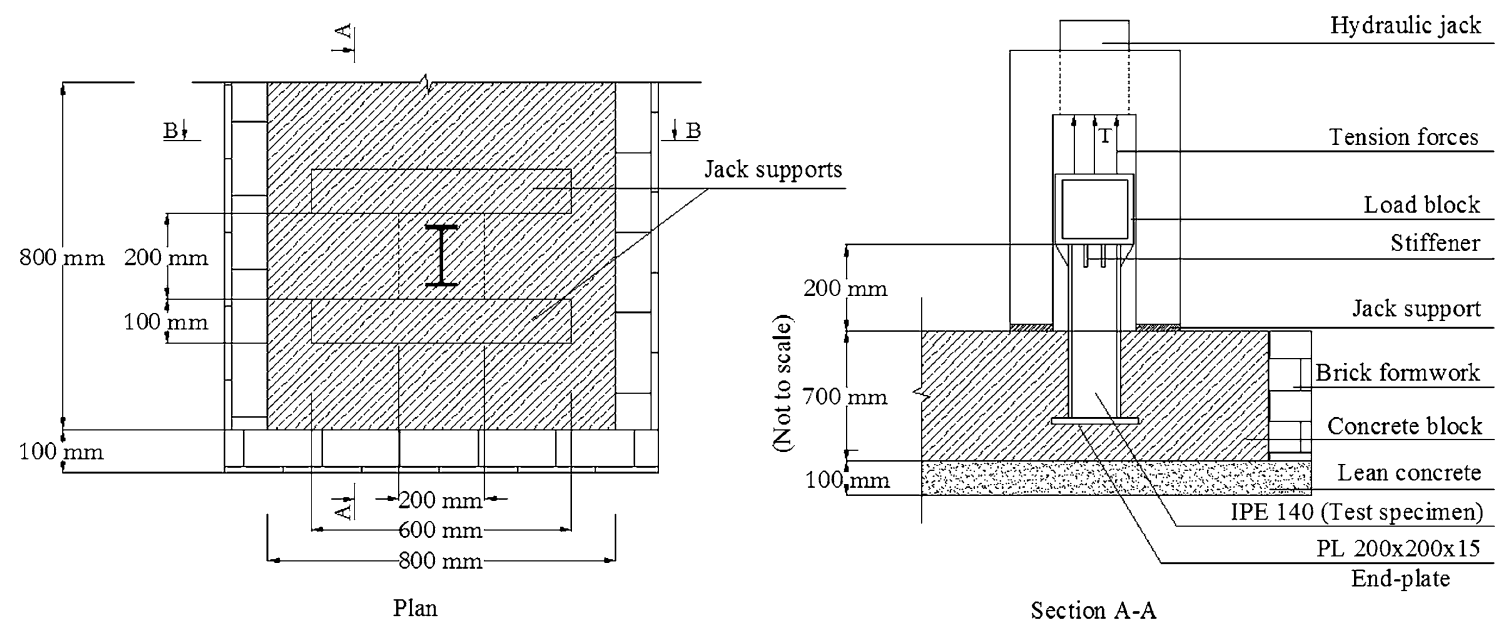

Fig. 6 Schematic details of test setup (plan and section)

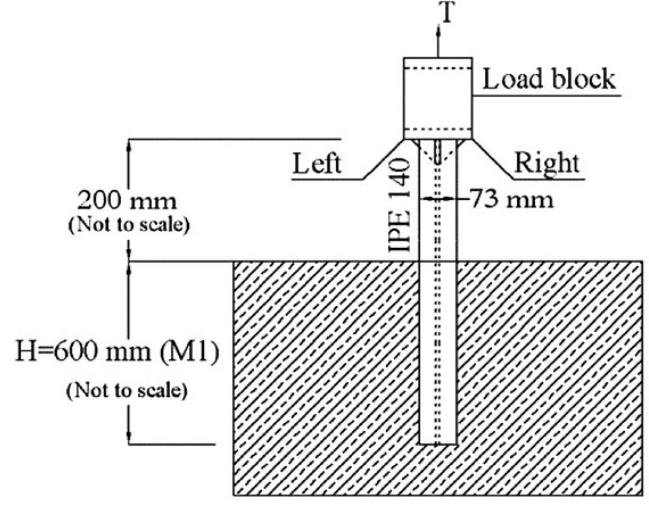

(M1)
Section B-B (Fig6)

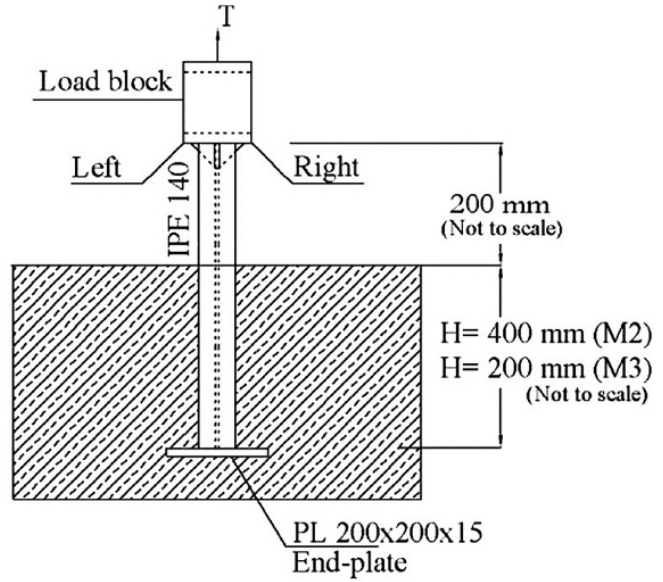

(M2 and M3)

Fig. 7 Section B-B of the experimental specimens M1 to M3

the section and of the jack. The ultimate failure loads of the tests were recorded to be 620 and $560 \mathrm{kN}$, for M2 and M3 tests, respectively. The breakage and failure of the profile started from one side of the flange and significant peeling of the painting of the flange was observed. The failures of the specimens are shown in Fig. 11a, b for M2, and Fig. $11 \mathrm{c}, \mathrm{d}$ for M3. The remaining stubs of the specimens are shown in Fig. 11b for M2 and Fig. 11c for M3. In Fig. $11 \mathrm{c}$, part of the crushed concrete around the profile has been removed.

\section{A discussion on the tests}

The experiments were set up to acquire information on the general and ultimate pullout strength of I-sections under three different conditions. Therefore, it was not the aim of the tests to provide information on the stress distribution along the embedded profile. Further, though the displacements of the

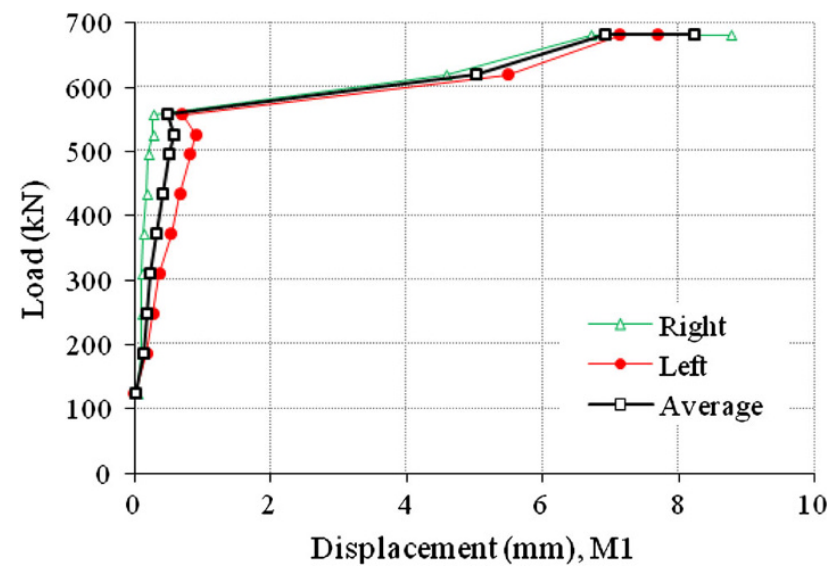

Fig. 8 Load-displacement diagram for specimen M1

top of the embedded (anchored) sections were recorded, however, the main focus of the tests was to evaluate the final 'strength' of the specimens. 
Fig. 9 Pullout of specimen M1
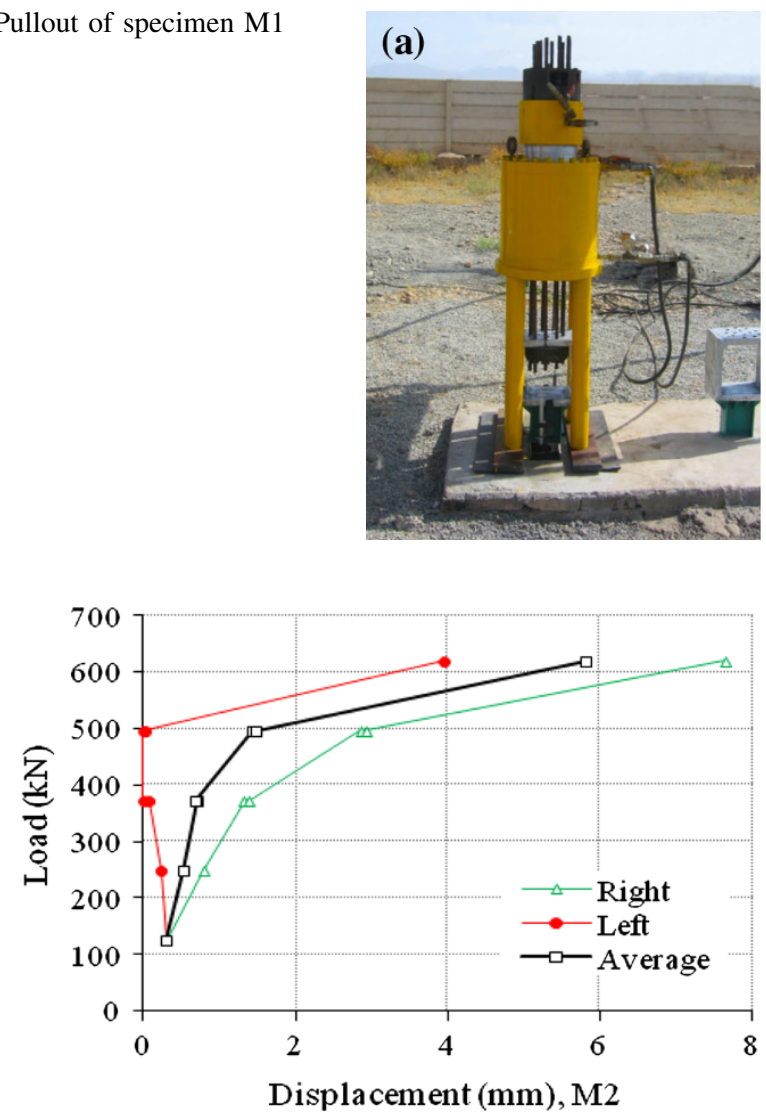
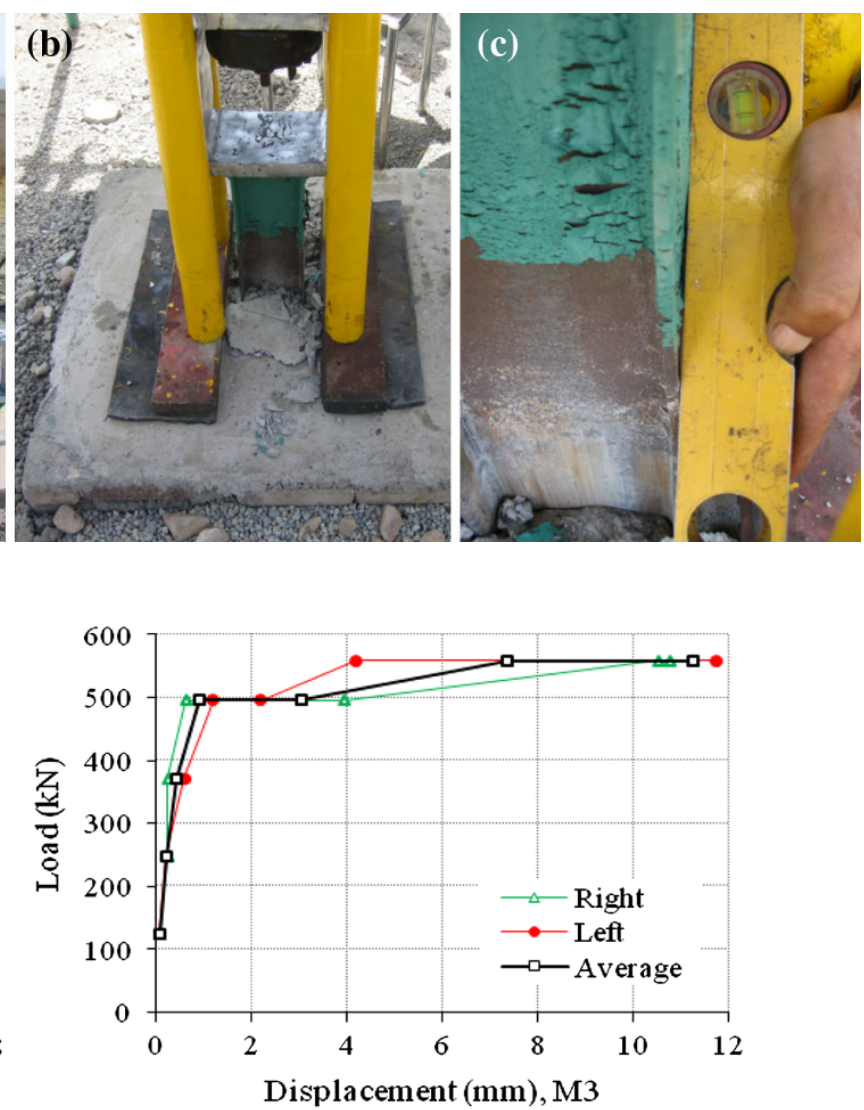

Fig. 10 Load-displacement diagrams for specimens M2 and M3

Fig. 11 Failure of specimens M2 (a, b) and M3 (c, d)
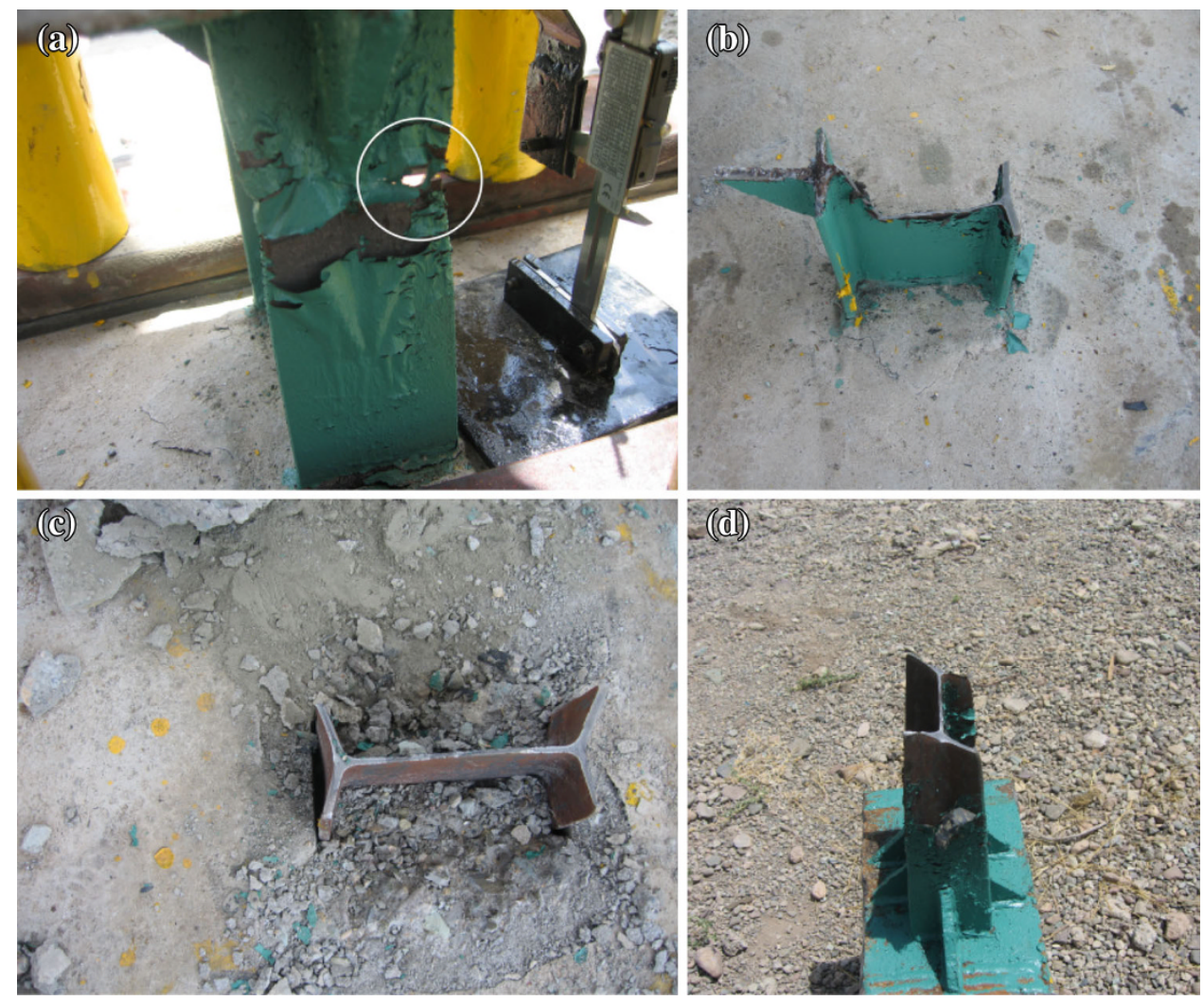
The specimen M1 had a combination of pulling out and yielding, at the same time, it showed a smooth and ductile behaviour. This specimen had identical section throughout the embedded length. For this specimen, the bond strength was the main resisting force against the pullout forces. The knowledge of strain and slip distributions along the embedded element, is the only way to get information on the interface constitutive relation and it has been a matter of study for several research workers. To discuss more on the nature of the bond strength, consider Fig. 12, which shows a number of steel elements embedded in concrete. The elements have different shapes, but for each element the cross-sectional shape is identical throughout the embedding length. Suppose that, these elements are subjected to a tensile (pullout) force. Most likely, the bond stress distribution around the surface of the plain round rebar S1, at a certain depth of embedment, say depth $\mathrm{h}$, will be the same. Similarly, the bond stress around the circular hollow section S3, will be the 'same', due to axial symmetry, but it will have different values for inside and outside surfaces (assuming that inside of the tube is also filled with concrete). In fact, under slight pullout load, the 'concrete column' inside tube S3, will separate from the main concrete, due to tensile stresses appearing at the bottom of the embedded tube. The same situation occurs

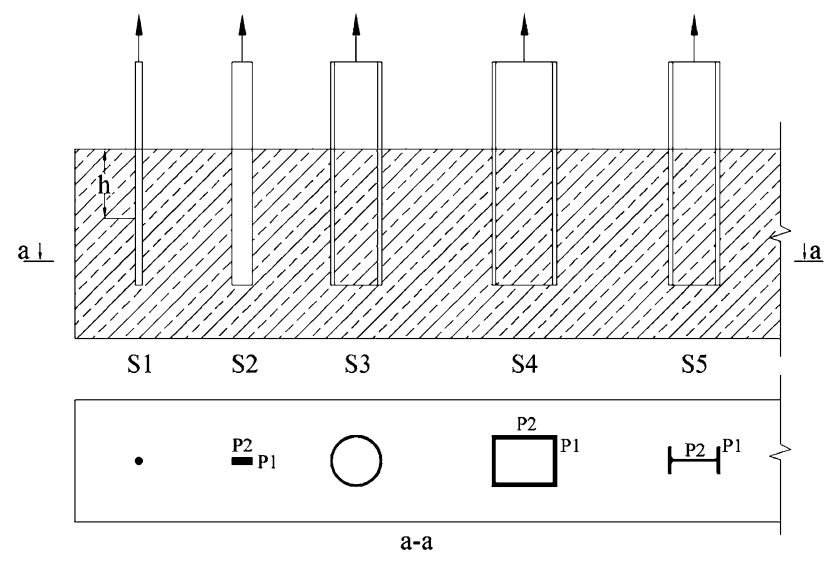

Fig. 12 A number steel sections embedded in concrete

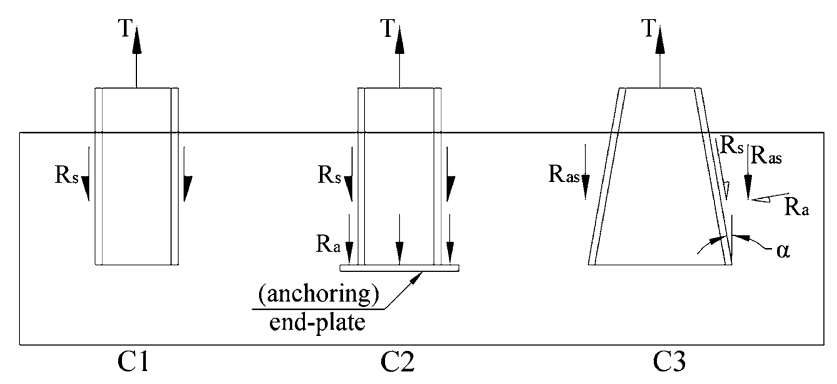

Fig. 13 Resisting forces against pullout for the concrete inside S4. For profiles S2, S4 and S5, there is not any data showing that the two distinct points, $p_{1}$ and $p_{2}$, would have the same bond stresses. Due to Poisson's effect, the bond stress around such sections will vary. For symmetric sections such as round rebar or tube, the heterogeneous nature of the concrete and interference of the aggregate size with the size of the section, could affect the bond stress round the perimeter of the section at a certain depth. Therefore, it is plausible that if, a slip data related to a certain range of rebar size would be 'exact' for, say a 'wire' (plain small size) rebar, due to its diameter size compared to the size of components of concrete. Presence of the reinforcement in actual construction of footings is another important factor which could affect the value of the bond stress.

In this regard, one of the test results reported by Pertold et al. (2000a) was to measure the bond strength between steel sections and concrete. Three HEB100 structural profiles were embedded in concrete blocks and were subjected to statically increasing pushout loads, till the signs of bond slip between concrete and steel were observed, when the specimens were considered failed. Dial gauges were used to measure the relative displacement of the steel column and the concrete base (near the point of the application of the load).

It appears that there is no more literature regarding the bond slip experiments on the embedded structural sections. However, a good number of test results have been reported on plain rebars (Abrams 1913; Weathersby 2003; Fabbrocino et al. 2002; Feldman and Bartlett 2005; Verderame et al. 2009). In general, in the pullout tests the amount of movement of the free end of the embedded bar was measured, but in reference (Weathersby 2003) the measurement of the strain was carried out at several places along the length of the embedded bar. However, applying this method to embedded steel elements would face the difficulty that the shape and geometric dimensions of the section might seriously affect the strain measurements. Therefore, such information will be useful only to a certain type (geometry) of the profile. In addition to the change in the shape (geometry) factor, which could be present in the steel profile, the scale (size) factor, would probably affect the results as well. In the light of the above discussion, it will be useful to obtain data on the global ultimate pullout behaviour of various embedded shapes, parallel to obtaining information on its local values of bond stress. Therefore, the experiments M1, M2 and M3, were devised more as a 'field' measurement/ experiment rather than having instrumented with delicate measuring apparatus.

Both of the tests M2 and M3 ended up with the breakage of the I-section under the tensile ultimate load together with a slight moment. Therefore, the specimens 


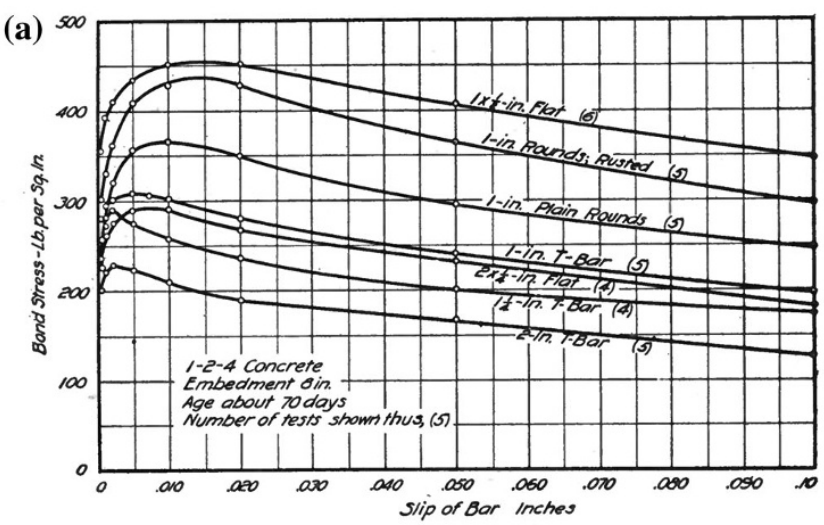

Fig. 17. Load-Slip Curves for Plain Round, Flat and T-Bars.

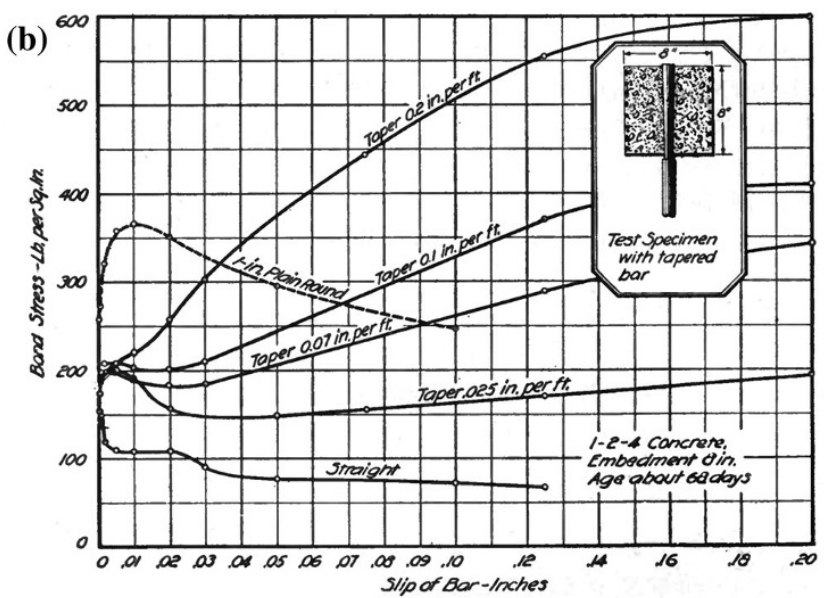

Fig. 18. Bond Resistance with Polished Bars of Wedging Taper. (c)

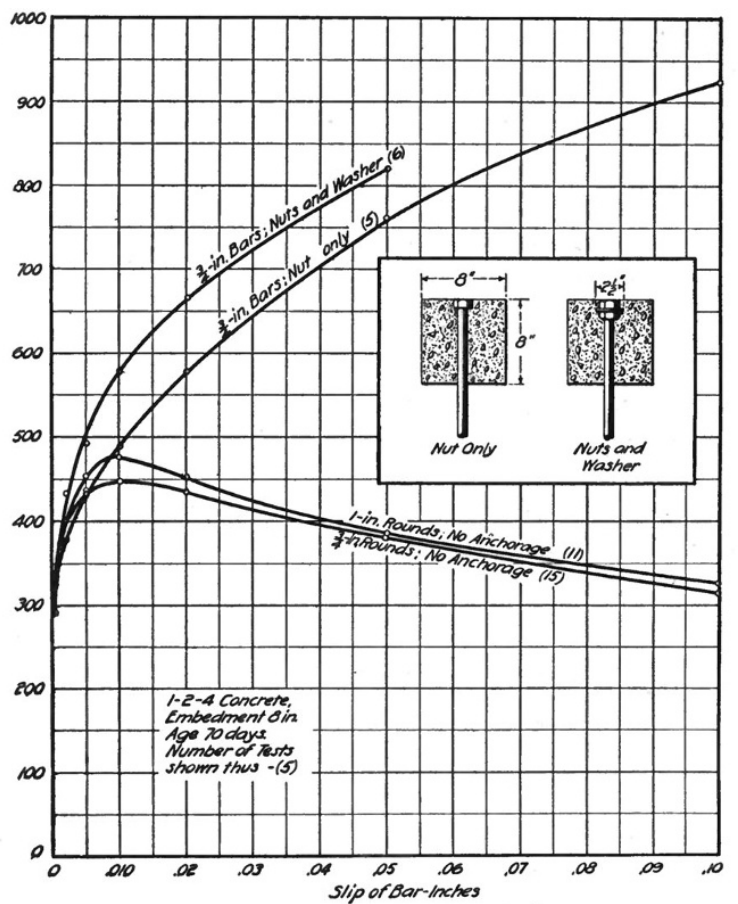

Fig. 37. LoAd-slip Curves for Bars Anchored with Nuts and Washers.

Fig. 14 Results of some pullout tests, Abrams (1913)

M2 and M3 which had end plates showed much higher resistance against pulling out. Considering the fact that the specimens M2 and M3 had 67 and $33 \%$ of the embedding length of the specimen M1, respectively, their extra pullout resistance was provided by their end plates. In comparison with test M1, the pullout behaviour of the tests M2 and M3 could be considered as a brittle behaviour.

Figure 13, shows three embedded steel elements under tensile force $T$. In the case of $\mathrm{C} 1$, where the surface of the steel element is parallel to the direction of $T$, the resisting force $R_{\mathrm{s}}$, is developed mainly by the bond slip. The major component of $R_{\mathrm{s}}$, is the shearing stresses. In the case of $\mathrm{C} 2$, with the presence of the (anchoring) end plate, a significant resisting component $R_{\mathrm{a}}$, is mobilised. The force $R_{\mathrm{a}}$, is closely related to compressive and punching resistance of concrete, and in comparison to $R_{\mathrm{s}}$, has higher unit stresses. Ozbolt et al. (2005, 2007) and Ožbolt and Eligehausen 1990 have presented finite element modelling of headed studs under pullout forces. Also, Yeun et al. (2012), have experimentally and numerically studied the headed studs. In the modelling, the main mobilised force relates to $R_{\mathrm{a}}$ of $\mathrm{C} 2$. In the case $\mathrm{C} 3$, the resistance of the inclined surface, against the pullout forces, will incorporate both types of bond slip $\left(R_{\mathrm{s}}\right)$, and anchoring $\left(R_{\mathrm{a}}\right)$, resistances. It could be anticipated that, the values of the stresses on such a surface depend on the inclination angle $\alpha$.

A smooth rebar may be anchored by providing a type of end hook, (Fabbrocino et al. 2002), or by fastening a nut... to its head (Eligehausen and Sawade 1989; Eligehausen et al. 1992). Figure 14, taken from the pioneering work of Abrams (1913), gives the results of a number of experiments on bond strength of (a) plain round bars, flat bars and T-bars, (b) wedging tapers, and (c) round bars anchored with nuts and washers. It is seen that, the wedging of the rebar or anchoring it, Fig. 14b, c, significantly, has increased the pullout resistance of the rebar. The results of these experiments are somehow comparable to the discussion related to Fig. 13. 
Fig. 15 Steel and concrete mechanical properties

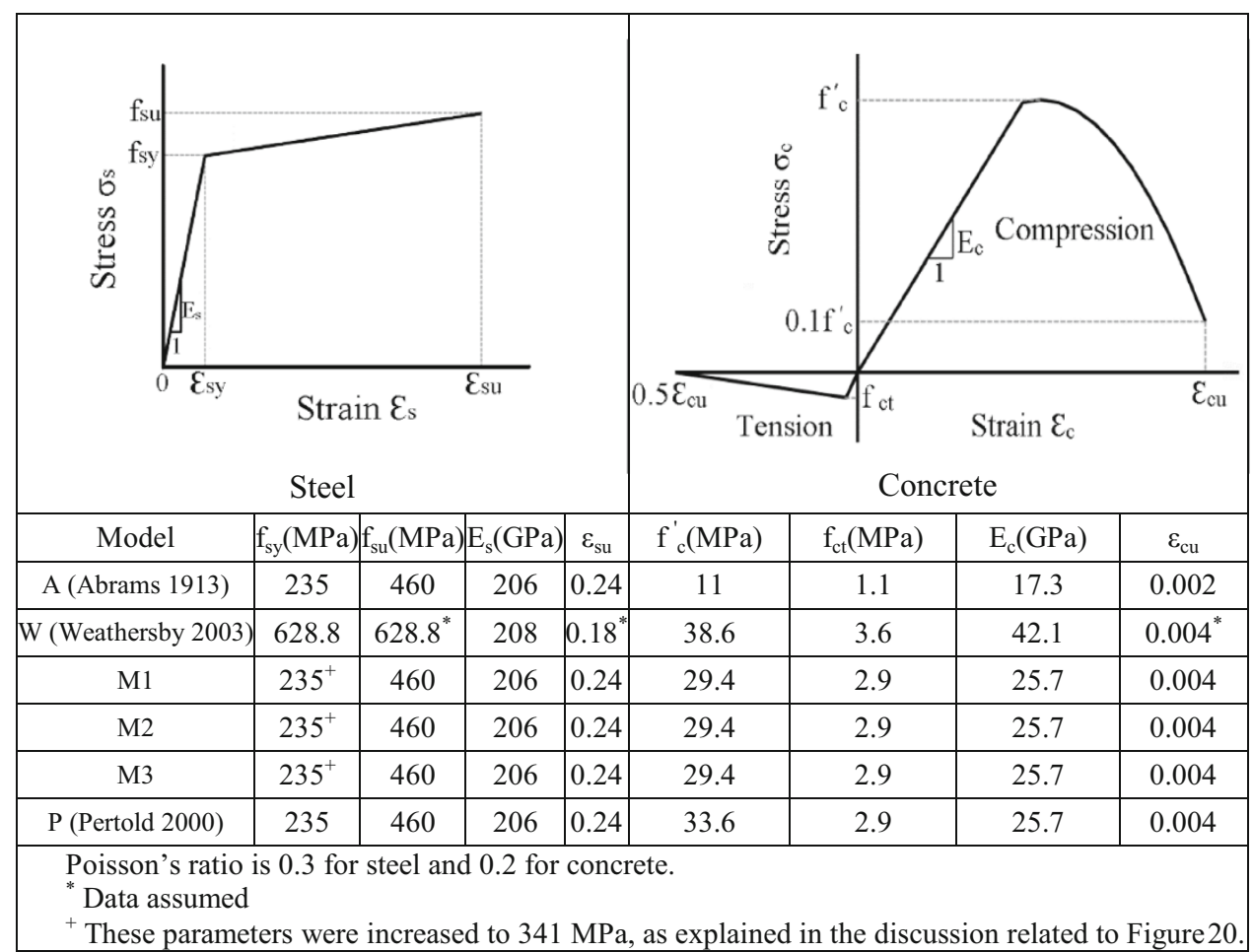

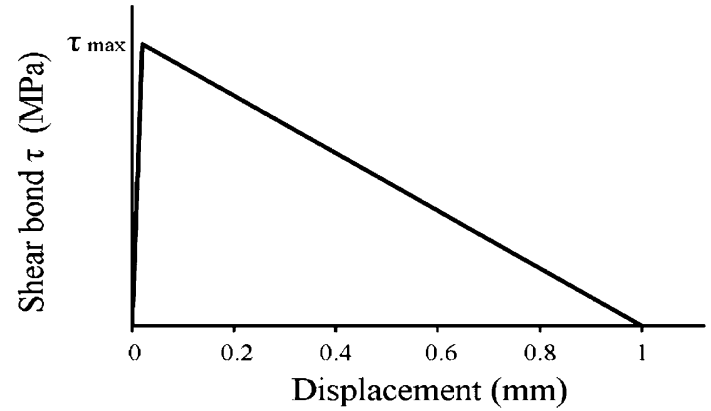

Fig. 16 Steel-concrete shear bond variation

\section{The numerical models}

Numerical models were generated to simulate the pullout tests for the experimental works mentioned in the paper. First, two numerical models were generated based on the results of the experimental works on the pullout strength of the plain rebar. These models are named ' $A$ ' and ' $W$ ' and are based on the data from the work of Abrams (1913), and Weathersby (2003), respectively. Models A and W are used to obtain the parameters related to the bond strength between concrete and steel. Also, models M1 to M3 are generated from respective tested specimens. Finally, model $\mathrm{P}$ is generated based on the experiments by Pertold et al. (2000b).

The modelling software is Abaqus 6.10-1 (2010), which has the capability of modelling nonlinear behaviour of both materials steel and concrete. The nonlinear dynamic explicit method of analysis with consideration of material and geometric nonlinearity is used. Also, the Abaqus element C3D8R is used for the finite element modelling.

Figure 15, shows the modelled material properties for steel and concrete. The type of modelling of concrete is 'damage plasticity' and is capable of simulation of monotonic loading, cracking and crushing (failure in tension and compression) of concrete, Wahalathantri et al. (2011).

For the bond strength, type of 'cohesive contact' together with coefficient of friction, possibility of separation and slippage was defined. The coefficient of friction was taken as 0.2 , and the steel-concrete shear bond variation with displacement, was assumed as in Fig. 16. The value of the parameters of Fig. 16 was found for model 'A', based on the calibration with the results of the respective experimental data.

Figure 17 shows the boundary conditions of the various models. The loading of the models were done by imposing displacements, because in this method the rate of the load increase with time could be controlled. For the models M1, M2 and M3 a uniform displacement of $10 \mathrm{~mm}$ (about the value observed in the experiments) was imposed at the free (top) end of the IPE section. For model P, according to the experiments a uniform axial displacement of $-0.8 \mathrm{~mm}$ (compressive) was imposed at the top of the HEB section. 
Fig. 17 Boundary conditions for the numerical models

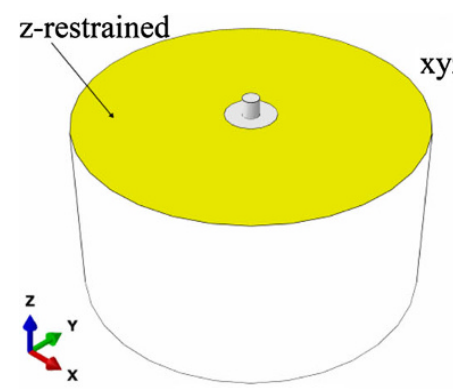

(A and $\mathrm{W})$

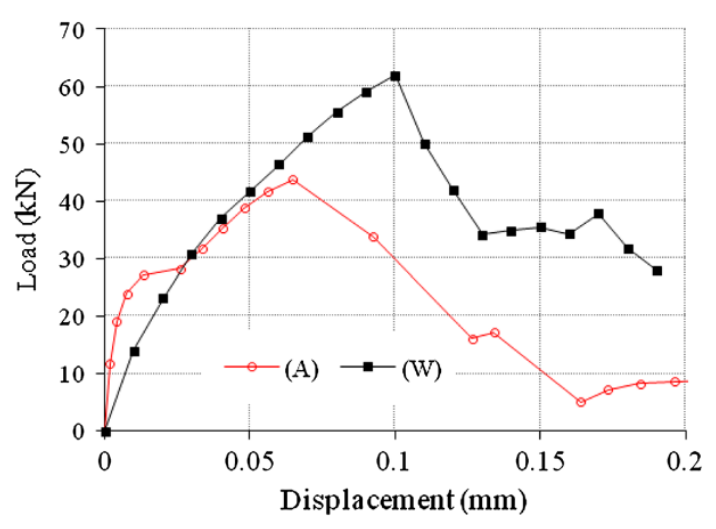

Fig. 18 Results of models A and W

\section{Results of the numerical models}

Figure 18 gives the load-displacement diagrams, at the bottom of the rebar, for models $\mathrm{A}$ and $\mathrm{W}$. For the experiment related to model $\mathrm{A}$, the measured bond stress 2.62 MPa, Fig. 14a (Abrams 1913), gives the total bond strength as $(25.4 \pi \mathrm{mm}$, the rebar diameter) $(203.2 \mathrm{~mm}$, embedded length) $(2.62 \mathrm{MPa})=42500 \mathrm{~N}(42.5 \mathrm{kN})$.

This is comparable with the peak value of model A, $43.8 \mathrm{kN}$. A similar comparison for model $\mathrm{W}$, gives the maximum bond strength $62 \mathrm{kN}$, compared with the experimental value $67 \mathrm{kN}$. The maximum shear bond, $\tau_{\max }$, for models $\mathrm{A}$ and $\mathrm{W}$, were assumed as 2.2 and $3.0 \mathrm{MPa}$, respectively, as shown in Fig. 16. The difference in the $\tau_{\max }$ values for models $\mathrm{A}$ and $\mathrm{W}$ is a reflection of the difference in the strength of the concrete of the two experiments, as recorded in Fig. 15.

The main reason in selecting a value for parameters involved in the numerical models was to obtain a good calibration with the related experimental results, however, it is noted that:

1. For most aspects of the models, a range of values, rather than a single value, is reported. For instance, according to Feldman and Bartlett (2005), the average bond strength varies in the range 0.98-2.2 MPa. Similar situation applies to coefficient of friction.

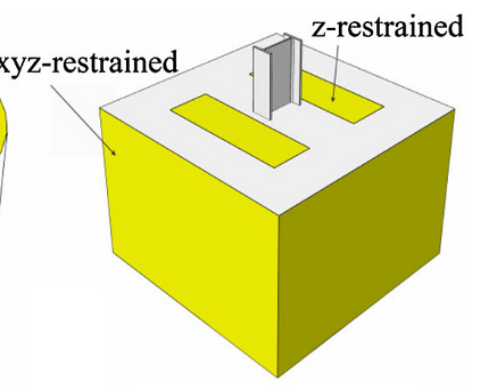

(M1, M2 and M3)

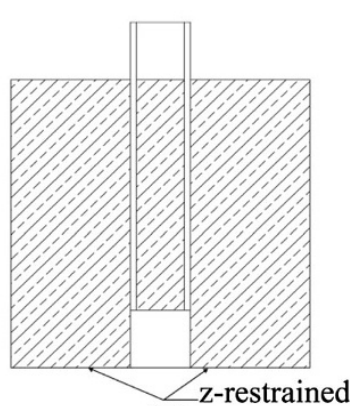

(P)
2. Some models are not sensitive to a certain range of values of a parameter. For instance, in models A and $\mathrm{W}$, the coefficient of friction and the plasticity parameters for steel were insignificant.

Figure 19 gives the load-displacement diagrams for the results of the models, as well as, the tests M1, M2 and M3. It is seen that, there is general agreement between the results. However, in the preliminary analyses, beyond the yield limit of the steel profiles, the numerical models did not show the capability of simulating the experimental records. To illustrate the reason for this, consider Fig. 20 which gives the normally used engineering stress-strain curve for the mild steel, together with the modelled steel diagram $\mathrm{OAB}$, as given in Fig. 15 and the 'magnified' diagram OCB. It is seen that the diagram OCB, more closely represents the normally used engineering steel behaviour than the diagram OAB. The magnified yield stress, is found from the test records as follows:

$f_{\text {sy }}^{+}=($Load at start of yielding $) /$

(The profile initial cross-sectional area).

For the test M1, the apparent start of yielding occurred at load $560 \mathrm{kN}$. Then $f_{\text {sy }}^{+}=341 \mathrm{MPa}=(560000 \mathrm{~N} /$ $1640 \mathrm{~mm}^{2}$ for IPE140). The magnified yield stress was used in the models instead of $235 \mathrm{MPa}$ for mild steel. This value of $f_{\text {sy }}^{+}$gave sensible results for M2 and M3 as well. These modified results are shown in Fig. 19.

For three models M1, M2 and M3, the parameter of the maximum shear bond defined in Fig. 16 had the value 3.0 MPa, the same as the model $\mathrm{W}$. The numerical diagram for model M1 shows a drop of load at displacement of about $9 \mathrm{~mm}$. In Fig. 19, both models M2 and M3, show higher values than the related experiments. This is because, in these models, the load was applied axially (that is, as a uniform displacement). However, in the tests M2 and M3, as shown in Fig. 11, a portion of the load was applied as bending moment (which was ignored in the modelling).

Figure 21 gives the variations of the bond stresses with respect to time, for models M1, M2 and M3. Since there is 
Fig. 19 Load-displacement diagrams for models M1, M2 and M3
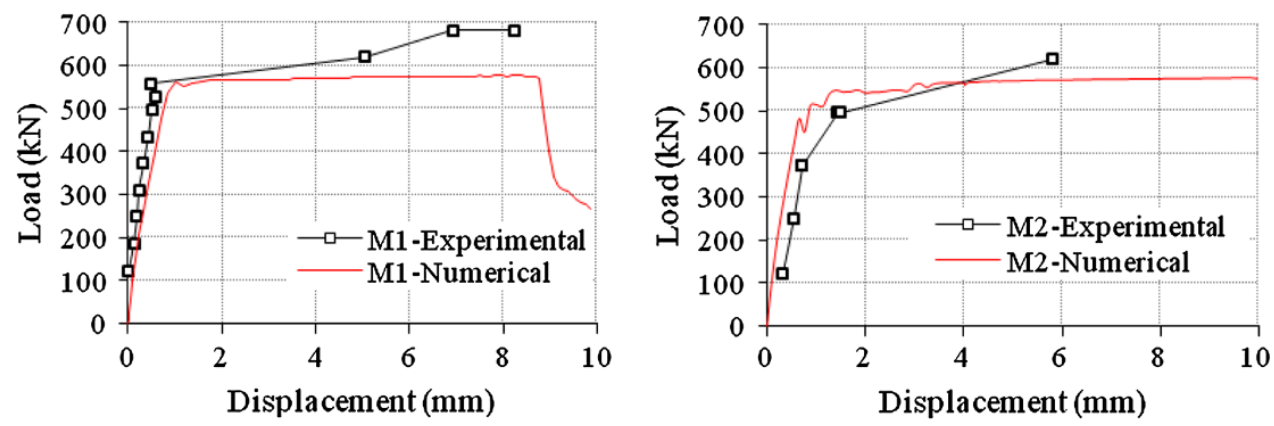

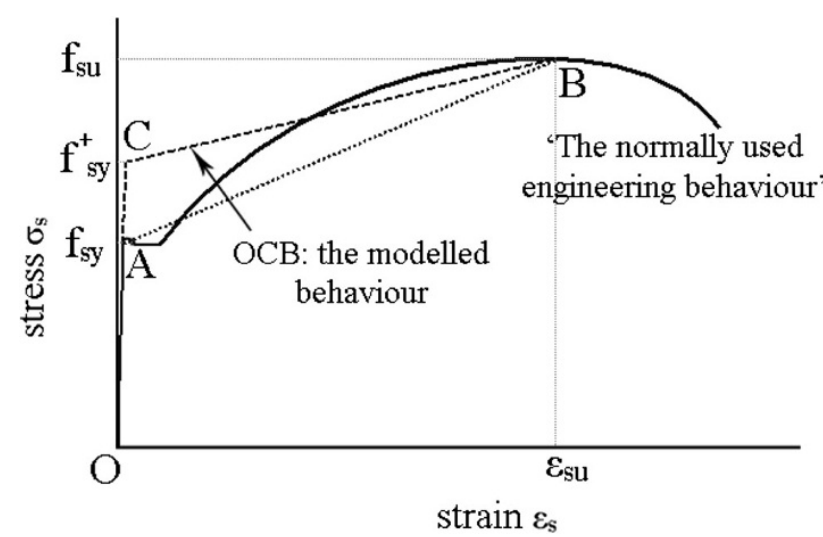

Fig. 20 The normally used engineering and modelled behaviour of steel

no end plate for test M1, therefore, all the pullout forces are resisted by the bond stresses (contact friction). For model M2, at the start, much of the resistance is provided by the bond stresses, but when the displacement level is reached $0.15 \mathrm{~mm}$, the role of the end plate (contact pressure) has increased. At the end, about half the pullout tensile force is resisted by the end plate. For model M3, the end plate came into effect at the displacement level of $0.1 \mathrm{~mm}$, and at the end, about $3 / 4$ of the load was transmitted by the end plate.

Figure 22, shows the stress distribution of the steel sections for models M1, M2 and M3. In Fig. 22, the uniform necking of the models M2 and M3 is due to the uniformly applied load (displacement).

Figure 23 represents the kinetic energy, as well as the internal energy, with respect to time for one of the models, namely M1. The diagram of the kinetic energy is almost coincident with the horizontal axis. The low value of the kinetic energy in Fig. 23, indicates that the rate of loading for the model is within an acceptable range for a static loading. This check is done for the other models as well.

The diagrams of Fig. 24 show the results of analysis, at the top of steel section, for model $\mathrm{P}$ together with the related experimental results. It is seen that there is a fairly good agreement between both results. For this model, $\tau_{\max }$ was $3.4 \mathrm{MPa}$.

\section{Concluding remarks}

The paper has studied the static pullout behaviour of embedded steel sections. Three pullout experiments for embedded IPE140 sections were conducted for this paper. Also, a discussion was given on the bond slip and the related experimental data. Then, numerical models of the experimental works were studied with Abaqus 6.10-1 (2010). Based on the experimental and numerical studies in this paper, the following remarks are made:

1. For specimen M1, that had identical cross-section within the embedding length, the main resistance source against pullout, was the bond stress.

2. The specimens M2 and M3 which had end plates, the bearing strength related to the end plates actually came into effect only after bond slippage occurred, see 'contact pressure variations' in Fig. 21. 
Fig. 21 Variations of the bond stresses for models M1, M2 and M3
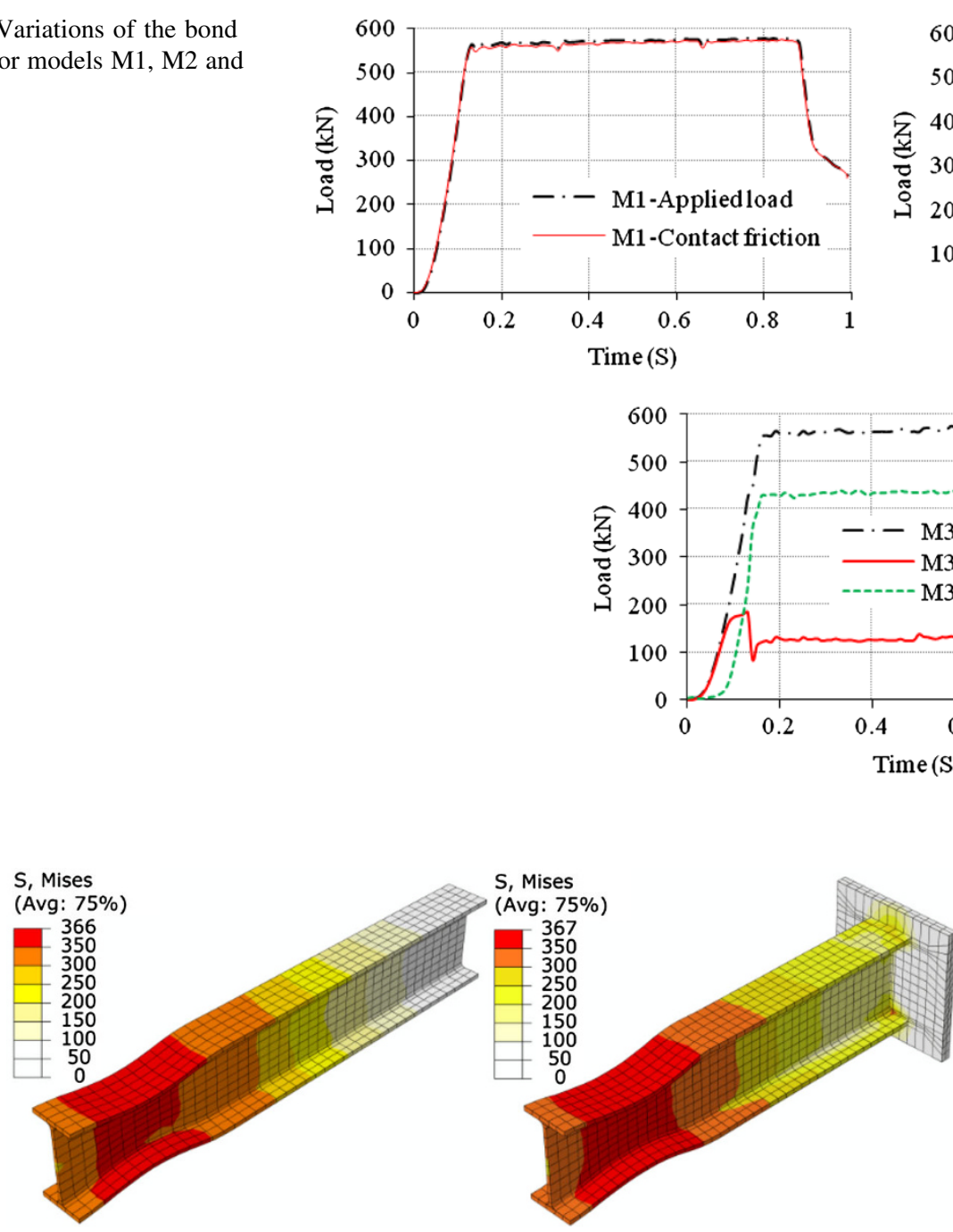
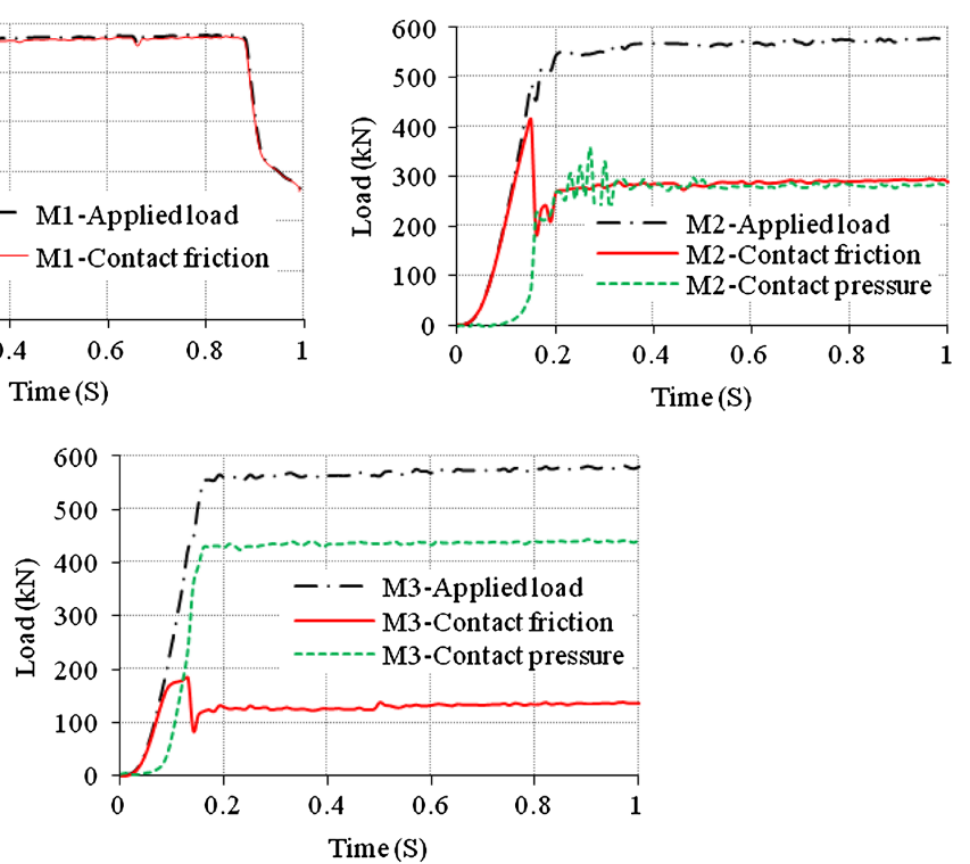

me (S)

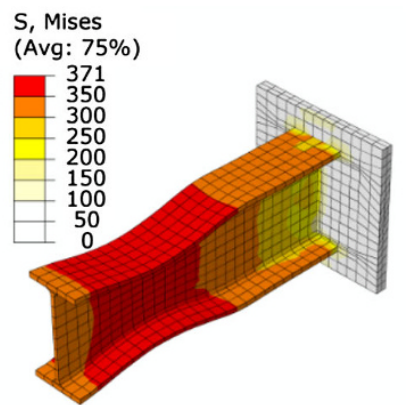

Fig. 22 Von Mises stresses (MPa) for models M1, M2 and M3

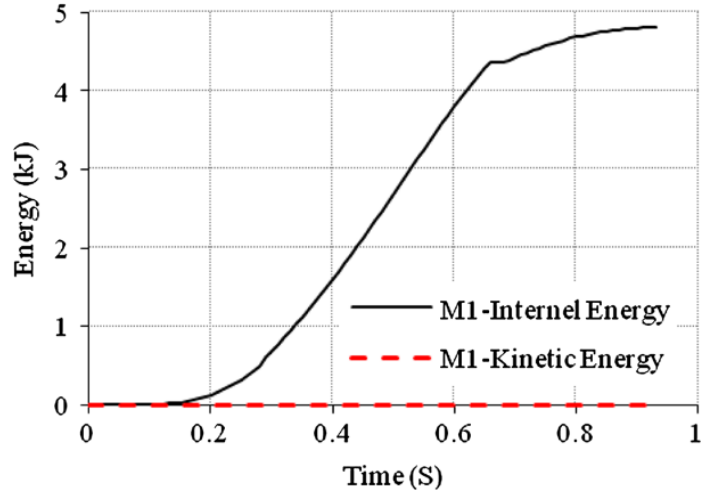

Fig. 23 Variation of kinetic and internal energy for models M1

3. As compared with experimental work, the numerical models with appropriate data and suitable software could simulate the tensile behaviour of an embedded column base more economically. At present, due to

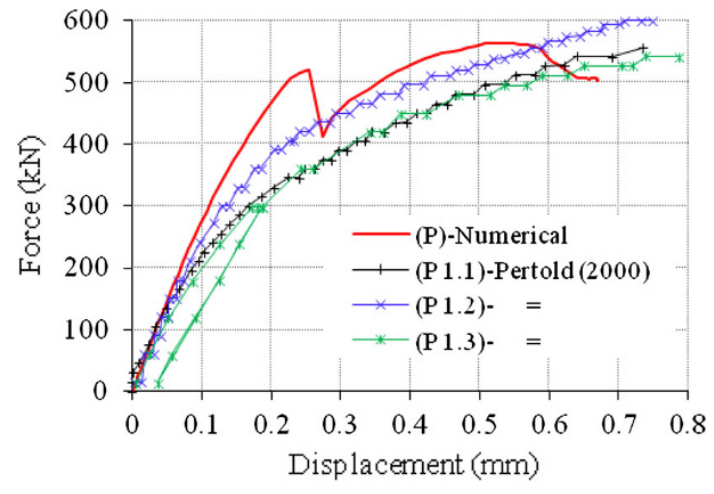

Fig. 24 Results for model P

lack of enough numerical case studies, some parameters of the models have to be calibrated with experimental work. In other words, the numerical results are not 'completely independent' yet, and have 
to be validated and verified. It is necessary that, appropriate ranges and trends of variation of the influential parameters for the numerical models to be studied, such that the results of the models of the already tested cases would not need calibration.

4. Despite the above remark, more experimental work is required to acquire deeper understanding of the pullout behaviour of embedded column bases. Tests having jack supports (reactions) far from the 'pull-out cone' region of the embedded structural sections would better simulate a static pullout condition in a real column base. Also, more experiments are necessary with varying geometries (and details) of embedded structural sections.

Acknowledgments The support of IA University South Tehran Branch is acknowledged. The authors also, wish to thank Messrs Sepehr Spatial Structures Company and Mr Ali F. Khiabani for their help and collaboration in carrying out the experimental work.

Open Access This article is distributed under the terms of the Creative Commons Attribution License which permits any use, distribution, and reproduction in any medium, provided the original author(s) and the source are credited.

\section{References}

Abaqus 6.10 (2010) Abaqus analysis user manual-Dassault Systemes Simulia Corp

Abrams DA (1913) Test of bond between concrete and steel. University of Illinois Bulletin No. 71, University of Illinois at Urbana-Champaign Urbana, IL

Eligehausen R, Sawade G (1989) A fracture mechanics based description of the pull-out behaviour of headed studs embedded in concrete. In: Elfgren L (ed) Fracture mechanics of concrete structures, Report of RILEM TC-90-FMA. Chapman and Hall, London, pp 281-299

Eligehausen R, Bouska P, Cervenka V, Pukl R (1992) Size effect of the concrete cone failure load of anchor bolts. In: Bazant ZP (ed) FramCoS 1. Elsevier applied science, Breckenridge, pp 517-525

Fabbrocino G, Verderame G, Manfredi G, Cosenza E (2002) Influence of smooth reinforcement on seismic capacity of joints in RC GLD frames. University of Naples Federico II, Italy

Feldman LR, Bartlett FM (2005) Bond strength variability in pull-out specimens with plain reinforcement. ACI Struct J 102(6): 860-867

Heristchian M, Motamedi M, Pourakbar P, Fadavi A (2014) Tensile behaviour of tapered embedded column bases. Asian J Civil Eng 15(4):485-499

Hitaka T, Suitaa K, Kato M (2003) CFT Column Base Design and Practice in Japan. In: Proceedings of the International Workshop on Steel and Concrete Composite Construction (IWSCCC-2003), Report No. NCREE-03-026, National Center for Research in Earthquake Engineering, Taipei, Taiwan. pp 35-45

Kohzu I, Kaneta K, Fujii A, Fujii K, Kida T (1991) Experimental study on very shallowly embedded type steel column-to-Footing connections. J Struct Constr Eng AIJ 421:59-68

Morino S, Kawaguchi J, Tsuji A, Kadoya H (2003) Strength and stiffness of CFT semi-embedded type column base. In: Proceedings of the International Conference on Advances in Structure, Sydney, Australia. pp 3-14

Nakashima S (1992) Mechanical characteristics of steel column-base connections repaired by concrete encasement. In: Proceedings of the Tenth World Conference on Earthquake Engineering, Madrid, Spain, pp 5131-5136

Nakashima S (1996) Response of steel column bases embedded shallowly into foundation beams. In: Proceedings of the Eleventh World Conference on Earthquake Engineering, Acapulco, Mexico

Nakashima S, Igarashi S (1987) Behaviour of steel square tubular column bases of corner columns embedded in concrete footings. In: Proceedings of International Conference on Steel and Aluminium Structures, Cardiff. pp 376-385

Ožbolt J, Eligehausen R (1990) Numerical analysis of headed studs embedded in large plain concrete blocks. Internal Report $\mathrm{Nr}$. 4/10-90/9, Institut fur Werkstoffe im Bauwesen, Stuttgart University, Germany

Ožbolt J, Kozar I, Eligehausen R, Periškic G (2005) Three-Dimensional $\mathrm{FE}$ analysis of headed stud anchors exposed to fire. Comp Concr 2(4):249-266

Ožbolt J, Eligehausen R, Periškić G, Mayer U (2007) 3D FE analysis of anchor bolts with large embedment depths. Eng Fract Mech 74:168-178

Pertold J, Xiao RY, Wald F (2000a) Embedded steel column bases-I: experiments and numerical simulation. J Constr Steel Res $56: 253-270$

Pertold J, Xiao RY, Wald F (2000b) Embedded steel column bases-II: design model proposal. J Constr Steel Res 56:271-286

Suzuki T, Nakashima S (1986) An experimental study on steel column bases consolidated with reinforced concrete studs: part 1-tests on steel column base under bending moment and shearing force. J Struct Constr Eng AIJ 368:37-48

Verderame GM, Ricci P, De Carlo G, Manfredi G (2009) Cyclic bond behaviour of plain bars. Part I: experimental investigation. Constr Build Mater 23:3499-3511

Wahalathantri BL, Thambiratnam DP, Chan THT, Fawzia SA (2011) Material model for flexural crack simulation in reinforced concrete elements using abaqus. In: Proceedings of the First International Conference on Engineering, designing and developing the built environment for sustainable wellbeing, Queensland University of Technology, Brisbane, Qld. pp 260-264

Weathersby JH (2003) Investigation of bond slip between concrete and steel reinforcement under dynamic loading conditions. $\mathrm{PhD}$ diss. Louisiana State University

Yeun KW, Hong KN, Kim J (2012) Development of a retrofit anchor system for remodelling of building exteriors. Struct Eng Mech 44(6):839-856 